\title{
An audit of non-urgent general adult referrals to Stikland State Psychiatric Facility
}

J Ras, $M B C h B$

L Koen, MB ChB, MMed (Psych), PhD

U A Botha, MB ChB, MMed (Psych), FC (Psych)

D J H Niehaus, MB ChB, MMed (Psych), FC (Psych), DMed

Department of Psychiatry, Stellenbosch University and Stikland Hospital, WCape

Objectives. The national Department of Health strongly advocates the strengthening of primary health care systems, and recommendations for appropriate level of care referrals exist. Very few published data on the scope of current ambulatory specialised psychiatric hospital services in South Africa are currently available, making it difficult to assess whether these recommendations are being followed. As a starting point, an audit was conducted to obtain a profile of new non-urgent general adult patients seen at Stikland Hospital with a view to evaluating system needs and demands.

Methods. The folders of 103 consecutively seen patients were selected for retrospective review. Patient demographic, referral and assessment information was entered into a single database. Descriptive statistics were compiled with reference to the above variables using SPSS.

Results. Overall $58.3 \%$ of referrals were from the private sector. More than a third (36.7\%) of referral letters stated no clear reason for referral and $41.7 \%$ no psychiatric diagnosis, and $29.1 \%$ of patients were referred without psychotropic medication being started. On assessment $62.1 \%$ of patients were found to have a single Axis I diagnosis. Despite virtually no referral letters making any mention of them, substance use disorders (30.1\%), personality traits/disorders (35.9\%) and co-morbid medical illness (36.7\%) were commonly found on assessment.

Conclusions. A significant portion of the patients in our sample could have been managed at primary care level and were referred prematurely. The overall quality of referral letters was poor, and they lacked vital information required for appropriate preassessment decision making. Undergraduate training focusing on these skills should be intensified, and consideration should be given to incorporating aspects of our findings into primary health care updates.

The national Department of Health strongly advocates the strengthening of primary health care systems with a specific focus on attempting to ensure that service delivery occurs at the appropriate level of care.' In accordance with this, the Western Cape Provincial Department of Health developed mental health care policy in alignment with the Mental Health Care Act (MCHA) of 2002.,3 This policy provides the foundation for rendering services according to a decentralised model, in a tiered system that allows for care at three levels. Ideally, the point of entry should be level 1 care (professional psychiatric nurse/medical officer) with up-referral as required, based on each case's complexity and the intervention needed. Level 2 care should be provided by general specialists and level 3 care at subspecialist clinics, e.g. neuropsychiatry.

Since this policy was implemented, we are not aware of any formal audit done at specialist psychiatric hospital outpatient level to determine whether the recommendations of the level of care guidelines are being followed. In fact, there is a paucity of published data available on the scope of current ambulatory specialised psychiatric hospital services in South Africa, or indeed the rest of Africa.

A retrospective analysis of 203 psychiatric outpatient folders conducted in Nigeria (published in 1978) revealed the most commonly recorded diagnoses to be anxiety neurosis, depressive neurosis and schizophrenia. ${ }^{4}$ Most of the referrals came from general practitioners and psychiatrists with presenting symptoms including 'heat sensation', paraesthesiae, sleep disturbances, pain and memory difficulties.

Stikland State Psychiatric Facility, a 340-bed hospital situated in the northern suburbs of Cape Town, services a catchment area comprising one-third of the Western Cape. Figures for the most recent 12-month period indicate approximately 500 contacts per month at the outpatient department. In line with Western Cape provincial policy, non-urgent appointments are only scheduled after formal referral by a mental health care provider. Although Stikland Hospital has a standardised referral form this is currently only provided on request (and mostly used by public sector referrers). Appointments are given within 14 days (depending on availability) of receiving the referral and all new outpatients have an assessment interview of at least 60 minutes. While all referral letters are screened by a consultant psychiatrist, the main purpose is not to assess needed level of care but rather to determine whether the patient should be evaluated urgently for admission or meets the minimum referral criteria, e.g. age, catchment area.

This audit represents the first attempt to obtain a profile of referral and assessment information for new non-urgent general adult patients at Stikland Hospital with a view to providing us with a snapshot of the current system needs and demands.

\section{Methodology \\ Data collection}

The folders of the 103 new general adult patients, aged 18 - 59 (inclusive), consecutively seen at Stikland Hospital's non-urgent first evaluation clinics (after 1 February 2010) were selected for audit. The government electronic patient capture system (Clinicom) was used to obtain a list of the folder numbers. All folders were available to 
the researchers and a total of 103 were included because on the day the 100th patient was assessed 3 other patients were also seen. Only health care providers could refer patients and no self-referrals were accepted. Patients who needed urgent assessment were managed as dictated by the MHCA. Folders were reviewed retrospectively and the relevant data were entered on a structured data sheet specifically designed for the study. Data included patient demographic and referral information, information pertaining to the assessment itself and the outcome thereof.

\section{Statistical analysis}

All data were entered into a single database. Descriptive statistics were compiled with reference to demographic, referral and assessment variables using the Software Package for Social Sciences (SPSS) (V10.0).

\section{Ethical considerations}

The study was approved by the Committee for Human Research, Faculty of Health Sciences, Stellenbosch University, and all their regulations were strictly adhered to.

\section{Results \\ Demographic information}

Data were collected for 62 female and 41 male referrals. Their demographic characteristics are summarised in Table I.

\section{Referral information}

The majority of the referrals were received from private practitioners with only $41.7 \%$ coming from the public sector. Referrals were received from across the spectrum of mental health care practitioners, but by far the majority came from general practitioners (55.34\%). The other sources of referral were psychiatrists (15.53\%), clinical psychologists (7.77\%), professional nurses (14.56\%), social workers (4.85\%) and other medical specialists (1.94\%).

More than one-third (36.7\%) of referral letters stated no clear reason for the referral, only citing one or more aspects of problematical client behaviour. A further $12.6 \%$ gave little clinical information, only stating financial or medical aid difficulty as main reason for referral (see Fig. 1 for a full summary). Concurrently, only 58.3\% of referral letters contained a clear DSM-IV-TR Axis I diagnosis, the rest only outlining broad symptom clusters. Only 3 letters made any reference to co-morbid medical illness, 3 to current or previous substance use and 3 to the presence of DSM-IV-TR Axis II traits or a diagnosis. At the time of referral $29.1 \%$ of patients were on no psychotropic drug at all, with a further $40 \%$ of the sample on only a single psychotropic drug (antidepressant 25.2\%, antipsychotic 12.6\% and lithium/mood stabiliser 2.2\%).

\section{Assessment information}

Fig. 2 provides a summary of the post-assessment Axis I DSM-IV-TR diagnoses, with $62.1 \%$ of patients having a single diagnosis. Current substance use disorders could be documented for $30.1 \%$, alcohol (12.6\%), benzodiazepines (11.7\%) and cannabis (8.7\%) being the

\begin{tabular}{|c|c|c|}
\hline & & $N$ \\
\hline \multirow{2}{*}{ Gender } & Male & 41 \\
\hline & Female & 62 \\
\hline \multirow[t]{4}{*}{ Language } & English & 28 \\
\hline & Afrikaans & 73 \\
\hline & Xhosa & 1 \\
\hline & Other & 1 \\
\hline \multirow[t]{4}{*}{ Ethnicity } & Mixed & 41 \\
\hline & Indian & 2 \\
\hline & Black & 2 \\
\hline & White & 58 \\
\hline \multirow[t]{5}{*}{ Education } & Grade 7 or below & 11 \\
\hline & Grade 8 - 10 & 28 \\
\hline & Grade $11-12$ & 47 \\
\hline & Post grade 12 & 14 \\
\hline & Not documented & 3 \\
\hline \multirow[t]{4}{*}{ Relationships } & Single & 59 \\
\hline & Divorced/separated & 14 \\
\hline & Married & 21 \\
\hline & Live-in partner & 9 \\
\hline \multirow[t]{4}{*}{ Employment } & Unemployed & 43 \\
\hline & Informal employment & 29 \\
\hline & Disability grant & 21 \\
\hline & Employed & 19 \\
\hline \multirow[t]{5}{*}{ Income status } & HO (disability grant) & 21 \\
\hline & $\begin{array}{l}\text { H1 (<R3 000/month) } \\
\text { H2 (R3 } 000-\text { R6 000/ }\end{array}$ & 51 \\
\hline & month) & 14 \\
\hline & H3 ( $\geq$ R6 000/month) & 5 \\
\hline & Private (medical aid) & 12 \\
\hline \multirow[t]{4}{*}{ Age } & 18 - 29 years & 34 \\
\hline & 30 - 39 years & 33 \\
\hline & 40 - 49 years & 25 \\
\hline & 50 - 59 years & 11 \\
\hline
\end{tabular}

most common substances of choice. A diagnosis (or set of traits) was documented on Axis II for 35.9\% of patients. The most common noted were borderline (48.65\%), antisocial (18.92\%), borderline and antisocial (5.41\%), avoidant (8.11\%) and dependent (8.11\%) personality disorder (or set of traits).

Significant medical illness was noted for $36.9 \%$ of patients on Axis III, hypertension (10.7\%) and diabetes (9.7\%) being the most common. Only 1 patient was confirmed to be HIV-positive. Numerous psychosocial and environmental stressors were noted. Of these, problems with the primary support system (46.6\%) and economic (45.6\%) and occupational issues (29.1\%) were most often recorded.

\section{Assessment outcome}

Special investigations were requested in 33\% of patients, with thyroid function and syphilis screening most prevalent, but HIV testing was requested in only $4.9 \%$ of cases and brain imaging in $2.9 \%$. Twenty- 


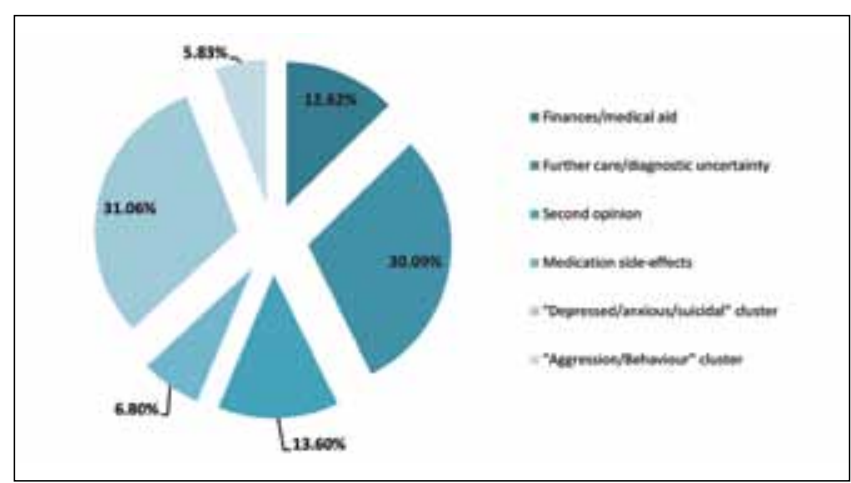

Fig. 1. Reasons for referral as per referral letter.

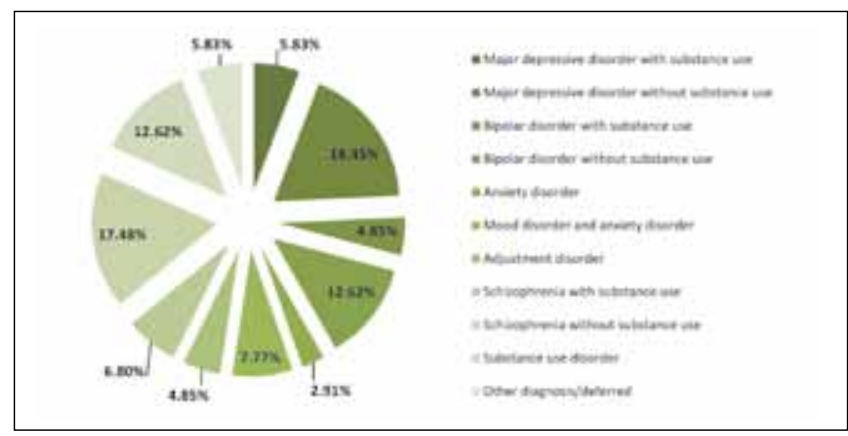

Fig. 2. Post-assessment DSM-IV Axis I diagnoses.

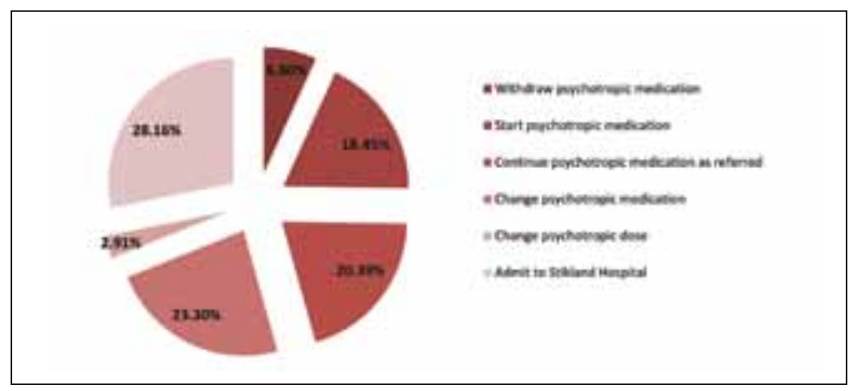

Fig. 3. Immediate post-assessment plans.

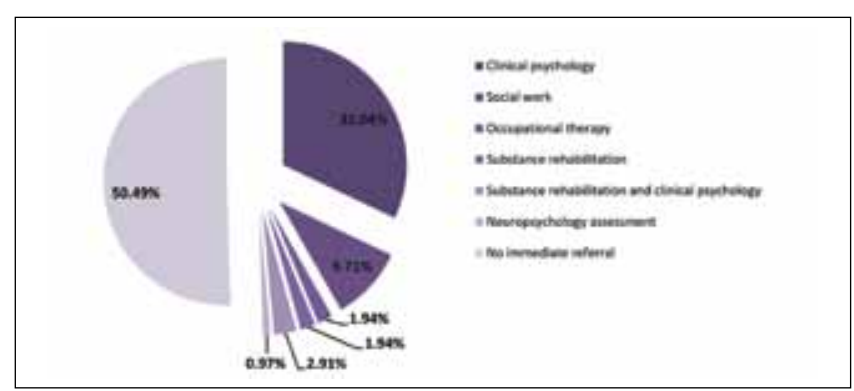

Fig. 4. Immediate post-assessment multidisciplinary referrals.

nine patients were admitted, 17 voluntarily, 8 with involuntary status and 4 assisted (MHCA 2002).

Immediate post-assessment plans and multidisciplinary referrals made are summarised in Figs 3 and 4, respectively. Only 14 of the patients did not receive a post-assessment follow-up appointment at Stikland.

\section{Discussion}

The fact that nearly $90 \%$ of the referrals in our sample led to either inpatient admission or follow-up at the outpatient department of Stikland Hospital would seem to indicate that level 2 care was needed and that the referrals were therefore appropriate. At face value this seems to support the notion that primary level services are managing to provide the level 1 care needed.

Unfortunately, on evaluation of the detailed results a slightly different picture emerges. In more than $40 \%$ of cases no psychiatric diagnoses were provided, leading us to surmise that the referrer was unsure of the diagnosis and therefore could not be relied upon to make an appropriate decision as to what level of care was needed. This is further supported by the fact that more than a third of referral letters did not state clearly why specialist referral was indicated. Also, nearly a third of patients were referred without having been prescribed any psychotropic medication. Evidence supports that many of these patients may have responded to first-line treatment, and in such cases the referral was probably premature..$^{6,7}$ It could therefore be argued that many patients received follow-up appointments not based on need for level 2 care, Stikland clinicians perhaps feeling ethically obliged to optimise level 1 care before referring the patient on to yet another system.

Referral information on co-morbid physical illness and substance use was woefully inadequate, as evidenced by comparisons with findings on assessment. Inadequate time spent on pre-referral interviews may have resulted in these omissions, but another even more worrying possibility is that referrers are not as cognisant as they should be of the direct impact both physical illness and substance use have on mental illness treatment outcomes. ${ }^{8-10}$

Personality disorders and/or traits also went virtually unreported. Possibly, referrers were reluctant to 'label' patients, but it is just as likely that proper assessments for the presence of suggestive features were not conducted. On assessment, nearly a third of patients were found to have traits (or a diagnosis) from the B cluster of personality disorders. These patients are known to have high rates of co-morbid mood, anxiety and substance use disorders and are often difficult to manage at level 1 care, especially when the diagnosis is not considered." These missed traits could have contributed to the symptom clusters of 'depressed/anxious/suicidal' and 'aggression/behaviour' that were stated on a number of the letters in the absence of a diagnosis.

The standard of the referral letters was in keeping with the results of a 2009 study conducted at the outpatient department of Pelonomi Provincial Hospital in the Free State. ${ }^{12}$ Results suggested poor-quality referrals, with only $25 \%$ of letters providing a medical history, $31 \%$ the past psychiatric history, $18 \%$ the physical examination findings and $15 \%$ the special investigation findings. Only $6 \%$ of referrers used an official diagnostic system, i.e. DSM-IV or ICD-10.

One other aspect that could have contributed to follow-up decisions was multidisciplinary referral. It is widely acknowledged that most 
psychiatric conditions are best managed in a multidisciplinary team setting according to the bio-psycho-social treatment model. ${ }^{13,14} \mathrm{~A}$ significant number of such referrals were made, and this cannot be discounted as a reason for patients receiving a follow-up appointment at Stikland Hospital independent of the level of care actually needed.

The demographic characteristics of the sample provide a fair representation of the larger catchment area population that Stikland Hospital serves. The large number of referrals received from general practitioners could account for the somewhat over-represented white group. With general practitioners being the main referral source, it could be argued that private-type patients are possibly more readily referred to specialist care. However, it has to be taken into account that all the community mental health nurses in our catchment area have direct access to a psychiatric registrar clinic for a half-day per week and often find it easier to first use this referral pathway. Almost $80 \%$ of referrals came from urban or semi-urban areas with more than half of the sample from the suburbs directly surrounding Stikland Hospital. This supports the notion that ease of access (i.e. proximity to services) increases likelihood of direct referral. Only 17 of the patients referred belonged to the state-classified highincome group (monthly individual income $\geq R 6000.00$ or monthly household/family unit income $\geq$ R8 333.33) or had medical aid, which seems to suggest that services where mostly utilised by patients who have no option other than to use state facilities.

A recent study of the prevalence of psychiatric disorders in South Africa reported the most prevalent classes to be anxiety disorders (15.8\%), substance use disorders (13.3\%) and mood disorders (9.8\%). ${ }^{15}$ In our sample, only $2.9 \%$ of patients were diagnosed with a pure anxiety disorder, while a further $7.7 \%$ had a co-morbid mood and anxiety disorder. While under-diagnosis of these conditions at primary level could account for this low incidence, other possible explanations should be considered. These include that these patients actually receive adequate level 1 care, that patients are not seeking treatment, or that they are being seen as not severely impaired and are therefore not being referred. Interestingly, data from a Free State community mental health care study also showed a paucity of diagnoses of anxiety disorders. ${ }^{16}$

Schizophrenia, with an estimated prevalence of $1 \%$, was overrepresented at $24.2 \%$ of the sample, possibly reflecting management issues with this illness in primary care due to difficulty in achieving adequate symptom control, high relapse rates and significant impairment of function..$^{17-19}$ It is also possible that referrers may feel less comfortable in treating patients with schizophrenia and therefore refer more readily. Worryingly, 30\% of patients met criteria for a substance use disorder. These findings once again support the dire need for dual diagnosis treatment programmes.

Special investigations were performed on 33\% of the sample after the initial assessment. Virtually all of these were standard, entry-level care screening investigations that serve to rule out commonly known, potentially treatable causes of mental illness.
Based on our assessment findings, we have to conclude that a significant portion of the referrals in our sample could have been managed at a primary care level and were therefore inappropriately referred. Unfortunately the overall poor quality of the referral letters makes these an inadequate tool to assist us in such decision making. One could argue that enforcement of a standardised referral form is an easy way to resolve this issue. However, taking into account the regularity with which certain types of information was lacking (e.g. no diagnosis, no information on co-morbidity), it is just as likely that the poor quality of many referrals could be due to many primary health care practitioners failing to adequately evaluate and therefore appropriately diagnose and manage psychiatric conditions. Therefore, rather than merely standardising what referral information is required we aim to look towards designing a more individualised feedback programme for our referrers, focusing on specific weaknesses in an attempt to re-train and therefore improve service delivery. Looking at the bigger picture, undergraduate training focusing on these skills should be intensified and consideration should be given to incorporating aspects of our findings into primary health care updates.

\section{Conclusion}

Our results have provided us with a good overview of current service status. We regard our findings as a vital first step towards informing future planning and ultimately implementation of appropriate guidelines to optimise ambulatory psychiatric services at our institution.

\section{References}

1. National Department of Health Website. www.doh.gov.za/docs/policy/norms/full-norms.html (accessed 1 February 2010)

2. Western Cape Provincal Government Gateway. www.capegateway.gov.za/Text/2004/11/ healthcare_2010_info.pdf (accessed 1 February 2010).

3. Mental Health Care Act No. 17 of 2002. Government Gazette 2005; 464(27300). Pretoria: Government Gazette. http://www.info.gov.za/view (accessed 4 May 2010).

4. Olukayode A, Jegede R. Outpatient psychiatry in an urban clinic in a developing country. Social Psychiatry 1978;13:93-98.

5. American Psychiatric Association. Diagnostic and Statistical Manual of Mental Disorders. 4th ed text revision. Washington, DC: American Psychiatric Association, 2002.

6. Trivedi MH, Rush AJ, Wisniewski SR, et al. Evaluation of outcomes with citalopram for depression using measurement-based care in STAR*D: Implications for clinical practice. Am J Psychiatry 2006;163:28-40.

7. Kahn RS, Fleischhacker WW, Boter H, et al. Effectiveness of antipsychotic drugs in first-episode schizophrenia and schizophreniform disorder: an open randomized clinical trial. Lancet 2008:371:1085-1097.

8. Vreeland B. Bridging the gap between mental and physical health: a multidisciplinary approach. Clin Psychiatry 2007;68(suppl 4):26-33.

9. Kessler RC. The epidemiology of dual diagnosis. Biol Psychiatry 2004;56:730-737.

10. Green Al, Drake RE, Brunette MF, Noordsdy DL. Schizophrenia and co-occurring substance use disorder. Am J Psychiatry 2007;164(3):402-408.

11. Skodol AE, Gunderson JG, Shea MT, et al. The collaborative longitudinal personality disorders study (CLPS): Overview and implications. J Pers Disord 2005;19(5):487-504.

12. Struwig W, Pretorius PJ. Quality of psychiatric referrals to secondary-level care. South African Journal of Psychiatry 2009;15:33-37.

13. Schotte CKW, Van Den Bossche B, De Doncker D, Claes S, Cosyns P. A biopsychosocial model as a guide for psychoeducation and treatment of depression. Depress Anxiety 2006;23:312-324.

14. Bustillo JR, Lauriello J, Horan WP, Keith SJ. The psychosocial treatment of schizophrenia: An update. Am J Psychiatry 2001;158:163-175.

15. Stein DJ, Seedat S, Herman A, et al. Lifetime prevalence of psychiatric disorders in South Africa. Br J Psychiatry 2008;192:112-117.

16. Lee T, Freeman M, Vivian W. Evaluation of mental health services in the Free State. S Afr Med J 1999;89(3):302-305.

17. Sparks A, McDonald S, Lino B, O'Donnell M, Green MJ. Social cognition, empathy and functional outcome in schizophrenia. Schizophr Res 2010;122:172-178.

18. Robinson D, Woerner MG, Alvir JM. Predictors of relapse following response from a first episode of schizophrenia or schizoaffective disorder. Arch Gen Psychiatry 1999;56:241-247.

19. Lindenmayer J. Treatment refractory schizophrenia. Psychiatr Q 2000;71(4):373-384. 